\title{
Posibility to fast react in order to identify the risk and make first claim assesment in case of a severe earthquake in Bucharest
}

\author{
Madalin ROSU \\ Bucharest University of Economic Studies, Bucharest, Romania \\ Rmadalin.rosu@gmail.com
}

\begin{abstract}
Insurer's reaction in case of a severe event, in Romania, especially in Bucharest is well known that is more than difficult, mainly due to the existing resources that need to be appointed in a short time to a high number of reported cases. The lack of a clear plan to react, at the national level, by all authorities is showing that Romania is not prepared properly to react in case of an earthquake similar with the one in 1977. Romanian authorities in the insurance industry strive to find a fast and smooth process, to inspect the claims in due time, but the reality shows that this plan is not linked to reality, and, as it is currently described as project by PAID will definitively fail to it purpose. Current legislative framework and procedures shows that the process of handling a claim in case of a big volume of files will be more than difficult even could lead to a blockage in the system. The authors' research follows the importance that claim inspection, identification of risk and claim file opening should have a total different process even a disruptive one via an online solution or special app. The research is starting from a plan of PAID which is mentioning that all resources available in the insurance companies to be combined and managed through a special command force under PAID supervision. The main finding of the research is that the Romanian insurance market need a totally different approach in order to assess the claims and in the same time the fact that currently discussed project, initiated by PAID cannot be applied in the existing environment due to many conflicts even with the EU legislation. A new modern solution to provide to the clients best services in the promised time is required to exist and to be applied in the moment of the event.
\end{abstract}

Keywords: Catastrophic claim management, solution for claims assessment, risk, earthquake.

\section{Introduction}

Taking into consideration the number of lives lost in catastrophic earthquakes during $20^{\text {th }}$ century, or in only one event like the one in March 1977, Romania is the $3^{\text {rd }}$ country as ranking, after Italy and Turkey in Europe.

To have a continuous focus on the subject is more normal and responsible from all authorities involved, not only from the insurance market.

ASF (financial supervision authority) requested to PAID a clear plan to react in case of a catastrophic event in Romania, as the earthquake is the most destructive event a draft of the plan was created. The biggest issue is the fact the whole construction of the pool is complicated. All processes are through facultative insurers (both the sales process as well the claim process). The structure of shareholding in PAID shows another issue which was not solved in the last 4 years, two shareholders are now in bankruptcy (Astra Asigurari and Carpatica Asig).

With respect to concept of insurance there is a question to be raised: how the pool and the whole insurance market is inspiring trust and credibility to their clients when $20 \%$ of the PAID shareholding is representing bankrupt companies?

In authors' opinion, the causes which led to the complicated system in mandatory household insurance are mainly linked with the political framework and a chaotic way of understanding the risk management in the market especially from the supervisory authority. Introducing a new risk in the law, for storms, without having a clear definition will impact directly the facultative household insurance. 
Couple of aspects to support the above statement:

1) Since the moment of PAID functioning 2010 until present days Romania failed to have a penetration degree of mandatory household insurance higher than $20 \%$. With this percent, which is mainly linked to facultative insurances Romania vulnerability in case of severe earthquake is more than obvious. Even having PAD policy is mandatory the system failed to apply penalties or to create a simple but effective campaign in order to stimulate the householders to insure their properties.

2) The previous events in terms of floods and landslides on a smaller scale showed to the entire market that the management of claims effectively is stumbling through complicated procedures and workflows

3) The new proposal from ASF to modify the existing Law 260/2008 in order to include more risk especially the storms show again that mixing risks from facultative insurance to the mandatory one is only cannibalizing the comprehensive coverage from facultative insurance, creating confusion towards the existing clients and making the sales process a bit ineffective and creating false hopes to the householders while the limit in PAD is 20.000 euro while in facultative insurance it depends on the value of the building and as well on the different risks covered.

The project led by PAID in terms of using shared resources under one coordination system started in the last quarter of 2019 and is still in progress. The concept is to use claim inspectors from all companies and allocate them according to the reported claims. The biggest issue here is that on claim inspector hired in company A could arrive in house insured by company $\mathrm{B}$. This type of approach is also in conflict with GDPR as well non ethical. As each insurer promised to their clients a specific time of response in case of a event, then the company should be allowed to follow the condition of the policy and not interfere in a valid contract only due to the fact that the specific client has a PAD policy and in the same area are more clients from different insurance companies covered by facultative coverage.

\section{Literature review}

Even the claims management in case of a severe earthquake represents a sensitive issue for the Supervisory Authority and the entire insurance Romanian market there is difficult to find some relevant scientific literature on this particular topic.

In case of an earthquake similar to that of 1977, the figures shows that they would be affected approx. 850,000 homes, that is over $10 \%$ of the country's housing stock, and material damages would be between 3.8 and 6.6 billion Euros, of which the value the damages related to the insured houses would represent approx. 1.5 billion Euros, according to AON Benfield calculation in 2017, using RMS catastrophe modeling; IF impact forecasting.

According to UNSAR statements only $19 \%$ from 9 million houses is covered via a PAD policy and only $16 \%$ is covered through a facultative insurance. This shows a major lack of coverage which can impact approx. 5 billion euro according to some calculation as mentioned above. 


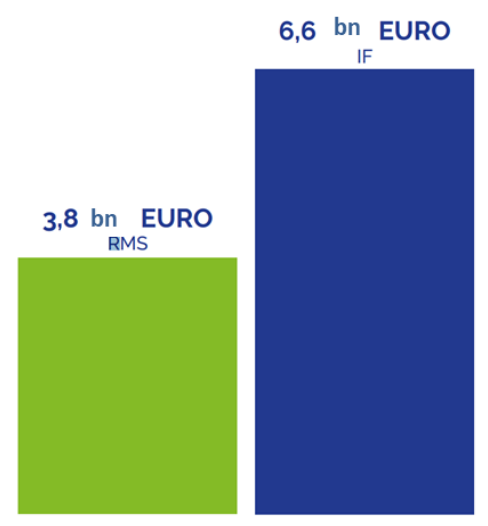

PICBE | 354

Figure 1. Example of AON catastrophe modeling 2017

Source: www.unsar.ro

Comparing Romanian market where a mandatory system for household insurance is in place we can observe that the penetration degree of insurance in other member states where this system is not existing is very high. As for example Czech Republic, Slovenia, Slovakia, Poland, we observe approx. 50\% penetration where in Hungary the percentage reached $70 \%$

Even in Romania we register probably the smallest percent of insured houses from our neighbors, we are the most exposed to a severe earthquake. So as short recap:

- Romania high exposure to earthquake

- Romania has a disaster pool (PAID)

- Romania has mandatory insurance for household

- Romania has one the lowest penetration degree of household insurance

- Romania do not have an effective plan to react effectively in case of a destructive earthquake

In this respect, the focus of the managing effectively the resources particularly in respect of claims management should be an important research topic.

\section{Research methodology and results}

Insurance companies need to know about all relevant natural catastrophe risks in their portfolio and need to be able to describe them individually. They have to consider the materiality and nonmateriality respectively. Relevant NatCat perils are flood, earthquake, windstorm, hail, subsidence/landslide and snow pressure.

The aim of the reinsurance department needs to be the correct estimation of risks in order to evaluate the NatCat exposure of a company. Insurers target is to protect the whole insurance portfolio with an appropriate level of reinsurance cover for all material NatCat risks. Therefore, majority of insurers buys reinsurance protection against the modeled 200-250 year event protection per peril.

The aim of the insurers is capturing of all NatCat risks of the portfolio, by taking into account their materiality in order to find out about relevant mitigation possibilities. To be able to identify all NatCat risks, the insurance company needs to establish detailed knowledge of its portfolio (e.g. how underwriting changes NatCat portfolio on a yearly basis or which measures are taken after occurred catastrophic events on a regular basis).

Insurance companies need to take account of the proportionality concept and focus on the material NatCat risks, especially when it comes to external modeling by the modeling agents. 
The process needs to include the know-how transfer from different vendor models as well as different views on the physical hazard from different modeling agents (where possible).

The consideration of NatCat risks is also of importance in the areas where no external models are available. The insurance company needs to describe the steps taken in such cases to ensure the appropriate reflection of NatCat risks in the partial internal model.

During 2018 and 2019 IRES published a study regarding Romanian perception towards household insurance. According to the study the following figures resulted from a sample of 1007 persons responding to the questionnaire.

Table 1. Most important risks perceived by Romanians according to IRES

\begin{tabular}{l|rrrrrr} 
Year & \multicolumn{1}{|l}{ Fire } & \multicolumn{2}{c}{ Earthquake Storm } & Theft & Flood & Landslide \\
\cline { 2 - 7 } 2019 & $65 \%$ & $57 \%$ & $50 \%$ & $40 \%$ & $30 \%$ & $19 \%$ \\
2018 & $54 \%$ & $56 \%$ & $46 \%$ & $29 \%$ & $34 \%$ & $21 \%$
\end{tabular}

Source: www.unsar.ro

According to the same study it was revealed that $71 \%$ from the population in 2019 are interested in household insurance compared with $74 \%$ in 2018 . Even the percent of interested people this is totally contradictory with the result in the market where only $20 \%$ of the population is insured against natural catastrophic events.

\section{Research methodology}

The research was done through analyzing paid and other entities as well on online and in the same time by participating to majority of meetings and conferences regarding insurance market.

By analyzing the PAID project, "Prometheus" it result in a high potential conflict with the insurance companies' procedures and their contracts already signed with the clients.

High level concept of the project is in the direction of fairness and common help during a crisis period which theoretically should end up fast.

\section{Table 2. Estimation of claim files according to portfolio according to PAID}

\begin{tabular}{|ccc|}
\hline Portfolio & $\begin{array}{c}\text { Estimation \# files } \\
- \text { earthquake- }\end{array}$ & $\begin{array}{c}\text { Estimation \# files - } \\
\text { flood- }\end{array}$ \\
\hline 1.500 .000 & 178.655 & 53.835 \\
\hline 1.700 .000 & 202.475 & 61.013 \\
\hline 3.000 .000 & 357.309 & 107.670 \\
\hline 4.000 .000 & 476.412 & 143.560 \\
\hline 5.000 .000 & 595.515 & 179.450 \\
\hline
\end{tabular}

Source: Author's own research

Taking into consideration that a frequency of $11-12 \%$ is underestimated due to the fact that was not taking into consideration the effect from the new apartments building constructed especially big cities like Bucharest. A minimum impact on top of the estimation above will consist in approx. $20 \%$ increase in total number of claim files especially from the new apartment buildings. 


\section{Research main results}

Starting with hypothesis based on which PAID has the intention to promote the project and catastrophic plan:

- The insurance market needs 4 months to realize the inspection of the damages in case of 200.000 claim files

- The resources needed: 522 claim inspectors out of which 422 to be available and mobilized

- Inspection of the claims is the most critical aspect based on this it is recommended that insurers will analyze to dimension their claims departments in order to fulfill the needs in case of a major event.

Table 3. PAID estimation based on RMS model for an event of 200 years RTP

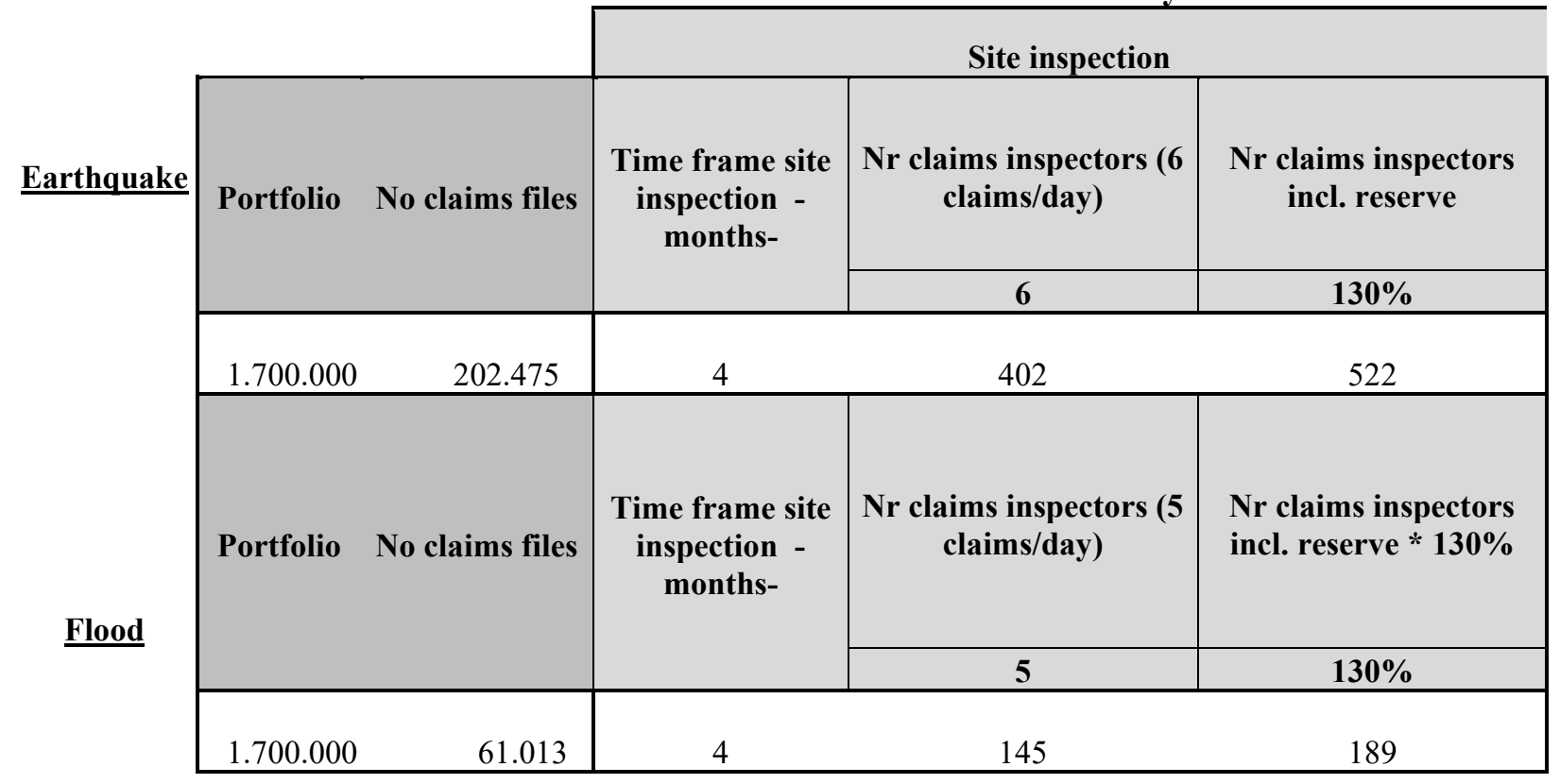

Source: PAID project estimation.

Analyzing the existing workflow it result the following process:

a) FNOL (first notification of loss) to the Insurer

b) Survey done by the Insurer

c) Handling of the claim file done by the Insurer

d) Payment of the file done by PAID

Basically the new process will be similar with the existing one with one single modification.

FNOL can be done through PAID as well.

The proposal is to have PAID as a coordination center at the market level to have information in real time in order to extend the capacity of taking over the FNOL's through a dedicated call center. The resources from insurance companies (claims adjusters) to be coordinated via PAID. In this way the business of each insurer will be in risk, while none of the insurers can respond in due time to the requests of clients.

Entering into details of the project it can be easily observed that mutualization of the resources available in the market will simply block the normal processes and flows of each insurer. We need to take into consideration that during the crisis period other type of claims will be reported 
(motor casco, health, life and so on). Having majority of resources at the disposal of PAID will bring a bad image to each insurer while impossible to solve the request of the clients.

\section{Proposed solution to respond to all requests from clients in due time}

Based on the day to day activities as claims responsible in one of the top companies in Romania and based on the research the author propose a solution for drafting a project at the market level in order to fast react to a catastrophic event

The present days are highly connected via mobile solutions and also internet. Taking this into consideration and as well the fact that in any case the insurance industry cannot provide in due time perfect survey, the insurance market need a disruptive solution.

For this an app or similar solution is highly needed. PAID can become a coordinator but only in virtual system.

\section{The context}

Without changing the general concept and framework we should establish couple of actions to be done urgently:

- Start to discuss with PAID and other stakeholders about a new IT platform (app)

- Create a project team to develop the idea and to build the concept

- Prepare the business analysis and find a company who can develop it in short time

- Plan to be discuss with brokers and intermediaries

- Test the solution with the integration to the insurance companies and brokers.

- Prepare and approve the payment solution to mobile "photographers"

\section{Solution description and methodology}

To be easy to understand the concept, the insurance market need fast reaction. Above was pointed out that this cannot happen due to many issues especially in regards with bureaucracy and overlapping resources from many insurers, each of them with particular procedures and methodology.

In order to imagine the whole concept of the application we need to understand the new workflow which can be performed through an intuitive application either on mobile or web based which can lead the client through the process or special user with the clear task to identify the risk, to make pictures and even to collect the documents

The application will give the possibility to use free resources to allocate and pick cases depend on the user type and as well can be transparent for the client.

In the same time the solution might be used as a communication tool between client, PAID and insurance company, in the same time all data in real time might be available to the interested parties (ASF, PAID, each insurer)

In order to have similar structure of data, each insurer should check and align the data structure in order to facilitate the communication within the application and as well to make the entire process faster:

a) Policy Information

Policy ID, Line of Business, Inception Date of Policy, End Date of Policy, Currency, Sum Insured Buildings (our share), Sum Insured Contents (our share), Sum Insured Business Interruption (our share), Gross Share (after coinsurance), Ceded Share Facultative Reinsurance, Type of Facultative Reinsurance, Ceded Share Obligatory Reins.

b) Location Details 
Policy ID, Country, Postcode, City, Street Name, Street Number, Apartment Number, Cresta, Longitude (X), Latit.(Y)

c) Peril Details

PolicyID, Peril, Sublimit, Building Sublimit, Contents Sublimit, BI Sublimit, First Loss

Sublimits, Deductible, Buildings deductible, Contents deductible, BI

d) Property Details

PICBE | 358

Policy ID, Occupancy type, Construction type, Roof Type, Number of stories, Storey of insured property, Basement, Soft Storey, Year built, Year of last consolidation, Raised ground flood, Floor type

\section{Process description}

The process should be guided and available for clients who want to use it for entire flow, as well for the agents as resources in the application. Short overview of the main characteristics of the application:

- FNOL (first notification of loss) in the application

- FNOL on the call center and call center operator will register the file and open a new command/order in the application so the users will see that a new file was registered and is ready to be inspected

- Allocate / nominate person will take the command and deliver within $24 \mathrm{~h}$ the full inspection / pictures with all the needed data.

- PAID may assign directly a free resource (claim inspector) when the command/order was not picked up in a specified time frame

- All documentation (including pictures\& movies) in regards with the claim will be submitted in the application through a simplified and guided process.

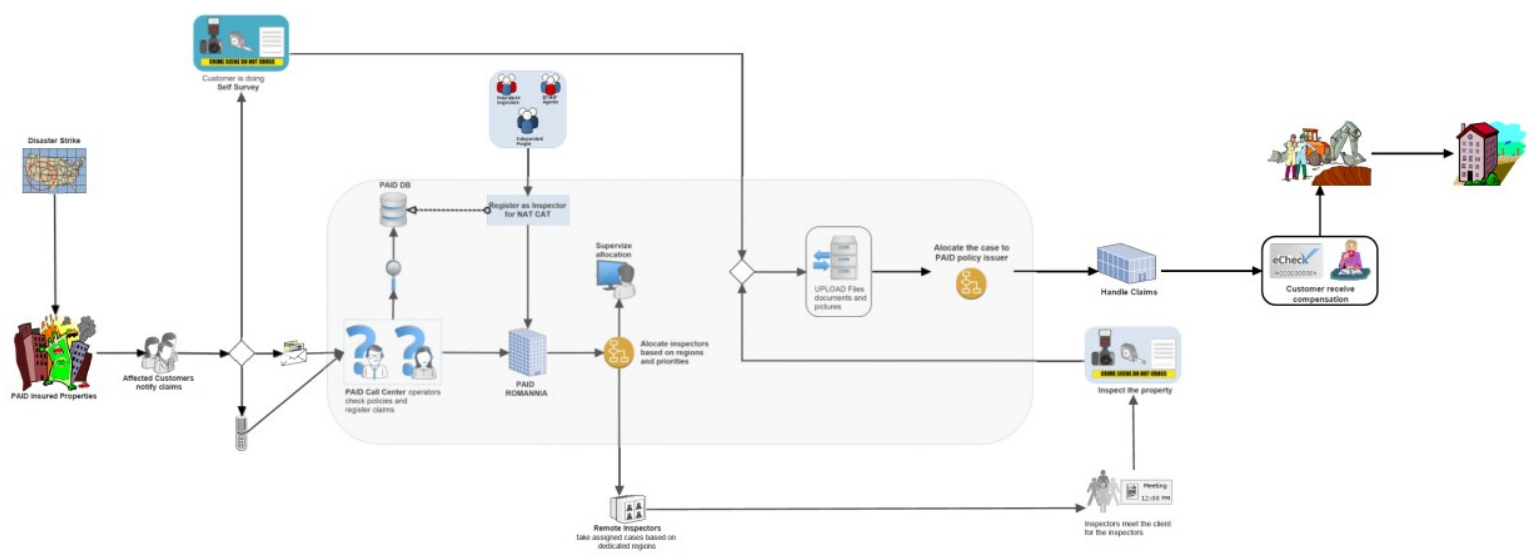

Figure 2. Example of a potential process inside application

Source: Author's own research

Step 1 - claim is registered in the application

The claim is registered in the database by the two possibilities (client directly or call center operator). A number of file is generated so as for the client who use the app. directly will have full access to the claim process inside the application 
Step 2 - identification of the policy in the database

During the process of claim registration the data of the insured will be automatically checked through PAID database in order to identify smoothly the insured person and the risk associated with.

While the client is holding also a facultative insurance, the connectivity via web services and api's to the databases on the facultative insurers will be necessary.

Step 3 - survey of the nominated risk

PICBE | 359

Based on the client option (self-survey or survey by appointment) the application will generate a specific workflow as follow:

- if the client option is for self-survey, then he/she will have access through a guided process by the camera of the smartphone and specific steps to be fulfilled (pictures inside and outside, documents uploading etc)

- if the client option is for survey by appointment, then the application will generate a command/ order (similar with "uber" or taxi system) and a free resource (claim inspector or broker) can pick up the order and deliver the service to the client

The difference between the workflows is that the client will have permanently access to the file progress while he/she was willing to realize the self-survey, while in the case of appointment once the survey was done, the job was solved in the application and the rest of client communication will be held by traditionally systems ( email, phone, letters)

Step 4 - handling of the claim file

For each claim, the insurers will have to assess based on prepared SLA (service level agreement) the files in a specific time frame. Based on the quantification of damages and an automatic triage from the application the claims will be standardized as follow:

Claims categories:

- total loss (including buildings with serious damages to structure)

- $\quad$ severe loss ( when the repair cost might arise $75 \%$ from the value without damages to the structure)

- low or medium loss

- loss only to the content (if client have a facultative insurance and the building was not affected)

Based on the companies procedures basically the claims handling process will remain in the pipeline according to the category of the claim, even might be difficult to be understand but the total losses will be the most simple cases to be handled after clear identification of risk and area affected.

Step 5 - payment of the claim file

It is recommended that after the handling process an automatic process of payment will be initiated by the application with a notification to the client as well for the resources involved in the process:

- notification in the application for the client which used the system as self-survey

- notification via sms or email for the client which used the classic system of notification via call center

While payment is realized, an automatic reporting tool online can provide information or aggregated data, to authorities or specific stakeholders in real time. 


\section{Conclusion}

A severe earthquake will be a reset moment for all, this mean insurance industry including. Observing the processes in the market on normal claims, in a market struggled by motor claims, in an industry which seems to be in a continuous debate between legislative changes and supervisory authority instability, to handle a wide and complex case as could be generated by an earthquake is more than a challenge to the market actors.

PICBE | 360

A simple and effective process is needed otherwise the whole insurance system will be in a delicate situation from reputational risk perspective and not only. While analyzing the concept of PAID proposal it is clear described that the target to finish all inspection for the notified claims will be approx. 4 months.

Such a term is not acceptable, in the author opinion and based on this a different disruptive solution should be taken into consideration. The access of the client should be easy and not bureaucratic.

Starting from the needs of the insurance companies and the need of the client, it is obvious that those two needs might met through a mobile application as the general trend in the society is to go more into the digital solutions.

The plus of the application is given by the fact that can integrate an important number of resources as brokers and broker's assistants or any authorized intermediary in the process, and the commands/ orders will be sent among specialized persons. According to the last estimation used in the media, there are in Romania approx. 17.000 people working in the insurance brokerage. If we compare such a tremendous potential resource with 522 inspectors needed as PAID mentioned in the project it is again obvious how we can speed up the process.

The most important aspect in a claim process from insurer perspective is to inspect the claim and identify properly the risk. The association with this important step is making clear photos and uploading document (as policy, or contract, invoices etc) and all of this might be simplified as time and the process through the presented application

Taking into consideration that after a catastrophic event, the number of the claims notified will make impossible for the insurance companies to deliver their services within the existing limits of the human resources, a different solution to handle such demands is clear needed. Another important aspect is that even all the insurers will be in the position to hire new people; the same issue will appear: lack of specialized resources in the market and the pressure of the time, so even here the application is delivering a potential income for the ones (brokers) who want to join in the system and delivering "inspection on demand"

Further development of the application and the entire process of managing claims in a stressful situation created by a severe catastrophic event should be carried on with the focus to simplify and to use modern solutions

\section{References}

Atkinson, G.M., and Boore, D.M., (1995). Ground-motion relations for eastern North America, Bull. Seism. Soc. Am., 83, p. 1778-1798.

Atkinson, G.M., and Boore, D.M., (1997). Some comparisons between recent ground-motions relations, Seismological Research Letters, Vol.68, Number 1, p.24-40.

Badea, D. (2003). Insurance \& reinsurance. Bucharest: Editura Economică.

Lungu, D., Arion, C., Aldea, A., and Demetriu, S. (1999). Assessment of seismic hazard in Romania based on 25 years of strong ground motion instrumentation, NATO ARW Conference on 
strong motion instrumentation for civil engineering structures, Istanbul, Turkey, June 2-5, $1999,12 \mathrm{p}$.

Tudor, B. (2002). Cutremurul risc asigurabil. Bucharest: Editura Niculescu

Rosu, M. (2019). Daunele in asigurarile auto. Bucharest: Editura Tandem Media

Radulian, M, Bonjer, K.P., Popa, M., and Popescu, E. (2007). Seismicity patterns in SE Carpathians at crustal and subcrustal domains: tectonic and geodynamic implications, in: PICBE | 361 Proceedings of International Symposium on Strong Vrancea Earthquakes and Risk Mitigation, p. $93-102$.

Onescu, M.C., Marza, V.I., Rizescu, M. and Popa, M. (1999). The Romanian earthquake catalogue between 1984-1997, in: Vrancea earthquakes: tectonics, hazard and risk mitigation, edited by: Wenzel, F., et al. 